\title{
The laboratory risk indicator for necrotizing fasciitis (LRINEC) scoring: the diagnostic and potential prognostic role
}

\author{
Ayman El-Menyar ${ }^{1,2,6^{*}}$ (D, Mohammad Asim², Insolvisagan N. Mudali ${ }^{3}$, Ahammed Mekkodathil $^{2}$, Rifat Latifi ${ }^{4}$ \\ and Hassan Al-Thani ${ }^{5}$
}

\begin{abstract}
Background: Necrotizing fasciitis (NF) is a devastating soft tissue infection associated with potentially poor outcomes. The Laboratory Risk Indicator for Necrotizing Fasciitis (LRINEC) score has been introduced as a diagnostic tool for NF. We aimed to evaluate the prognostic value of LRINEC scoring in NF patients.

Methods: A retrospective analysis was conducted for patients who were admitted with NF between 2000 and 2013. Based on LRINEC points, patients were classified into (Group 1: LRINEC < 6 and Group 2: LRINEC $\geq 6$ ). The 2 groups were analyzed and compared. Primary outcomes were hospital length of stay, septic shock and hospital death.

Results: A total of 294 NF cases were identified with a mean age $50.9 \pm 15$ years. When compared to Group1, patients in Group 2 were 5 years older $(p=0.009$ ), more likely to have diabetes mellitus (61 vs $41 \%, p<0.001$ ), Pseudomonas aeruginosa infection ( $p=0.004)$, greater Sequential Organ Failure Assessment (SOFA) score $(11.5 \pm 3$ vs $8 \pm 2, p=0.001)$, and prolonged intensive care (median 7 vs 5 days) and hospital length of stay ( 22 vs 11 days, $p=0.001$ ). Septic shock (37 vs. $15 \%, p=0.001$ ) and mortality ( 28.8 vs. $15.0 \%, p=0.005$ ) were also significantly higher in Group 2 patients. Using Receiver operating curve, cutoff LRINEC point for mortality was 8.5 with area under the curve of 0.64 . Pearson correlation analysis showed a significant correlation between LRINEC and SOFA scorings $(r=0.51, p<0.002)$.
\end{abstract}

Discussion: Early diagnosis, simplified risk stratification and on-time management are vital to achieve better outcomes in patients with NF.

Conclusions: Beside its diagnostic role, LRINEC scoring could predict worse hospital outcomes in patients with NF and simply identify the high-risk patients. However, further prospective studies are needed to support this finding.

Keywords: Necrotizing fasciitis, LRINEC score, SOFA score, Prognosis, Sepsis, Outcomes

\section{Background}

Necrotizing fasciitis (NF) is a rare but rapidly progressive devastating soft tissue necrosis that usually involves fascia and subcutaneous tissues with a significant hospital morbidity and mortality [1-3]. It has been estimated that 13 per million of populations are hospitalized each year for NF, of them $20-30 \%$ dies. The mortality rate could reach up to $100 \%$ in the absence of the proper and timely diagnosis and treatment [4]. The most

\footnotetext{
* Correspondence: aymanco65@yahoo.com

${ }^{1}$ Clinical Medicine, Weill Cornell Medical School, Doha, Qatar

${ }^{2}$ Clinical Research, Trauma Surgery, Hamad General Hospital (HGH), Doha, Qatar

Full list of author information is available at the end of the article
}

common risk factors for NF are diabetes mellitus (DM), immunodeficiency diseases, illicit drug use and malnutrition [1]. This kind of infection can occur with a trivial wound or often without any provocation [5-7]. Early diagnosis, aggressive serial debridement, broad-spectrum antibiotics and multidisciplinary critical care approach are vital to attain favorable outcomes in NF patients $[3,4,8]$. The Laboratory Risk Indicator for NF (LRINEC) is a scoring system driven from six routinely performed laboratory tests and used initially to early distinguishing NF from the other severe soft tissue infections [9]. Multiple studies have assessed the utility of LRINEC for the early diagnosis of NF and found that it can be used for identification and classification of NF patients into 
different risk categories that subsequently facilitates the appropriate management of hospital resources [10, 11]. However, few studies have observed an association between LRINEC scoring values and outcomes in patients with NF $[5,12-16]$. There is always a need to find a simplified bedside, validated, rapid tool to early stratify patients with a potential life-threatening illness. The present study aims to evaluate the role of LRINEC score as a prognostic tool for in-hospital outcomes in patients with NF.

\section{Methods}

A retrospective analysis of prospectively collected data of patients who were admitted to the surgical intensive care unit with a provisional diagnosis of NF regardless of age, sex and ethnicity, was performed. The study was conducted between 2000 and 2013 at Hamad General Hospital (HGH), which is the only tertiary care facility in the state of Qatar. We excluded any cases with incomplete relevant data or inaccurate diagnosis. Collected data included patients' demographics, clinical presentations, site of infection, type of comorbidities, microbiological and laboratory findings. Primary clinical outcomes were ICU and hospital stay as well as in-hospital mortality.

NF was diagnosed based on clinical and laboratory assessments on arrival and during the hospital stay including clinical criteria by the Center for Disease Control and Prevention and the National Necrotizing Fasciitis Foundation and scoring $[1,2]$. When clinical assessment and surgical exploration were equivocal, the final diagnosis of NF in our study was made based on confirmatory histopathologic analysis. Also, a Gram staining at primary debridement is obtained and intraoperative frozen section biopsy is performed whenever there is a suspicion for NF, requiring exploration. Septic shock was defined as sepsis-induced hypotension (i.e., systolic blood pressure less than $90 \mathrm{mmHg}$ (or a fall in systolic blood pressure of $>40 \mathrm{mmHg}$ ) persisting despite adequate fluid resuscitation [12]. LRINEC was calculated at presentation using laboratory results of six variables $\mathrm{C}$-reactive protein (CRP), white blood cell count, hemoglobin, sodium level, creatinine and glucose (Table 1) [9]. For this study analysis, we included only patients who fulfilled the required laboratory findings to calculate LRINEC score. Patients were stratified according to the LRINEC scoring points into two groups; score $<6$ (Group 1) and $\geq 6$ (Group 2) to study different characteristics and outcomes. SOFA (Sequential Organ Failure Assessment) score was calculated using parameters such as the ratio of partial pressure arterial oxygen and fraction of inspired oxygen ( $\mathrm{PaO} 2 / \mathrm{FiO} 2)$, platelets count, bilirubin level, Glasgow coma score, Mean Arterial Pressure (MAP), use of vasopressors, creatinine level and urine output [17]. NF has been classified into different groups (I-IV) based on microbiological cultures (Table 1) [18].
Table 1 Study definitions

\begin{tabular}{|c|c|}
\hline \multicolumn{2}{|c|}{ Laboratory Risk Indicator For Necrotizing Fasciitis } \\
\hline Variable (units) & Score points \\
\hline \multicolumn{2}{|c|}{ C-Reactive Protein (CRP) (mg/L) } \\
\hline $\begin{array}{l}<150 \\
>150\end{array}$ & $\begin{array}{l}0 \\
4\end{array}$ \\
\hline \multicolumn{2}{|c|}{ White blood cell count (per $\mathrm{mm}^{3}$ ) } \\
\hline $\begin{array}{l}<15 \\
15-25 \\
>25\end{array}$ & $\begin{array}{l}0 \\
1 \\
2\end{array}$ \\
\hline \multicolumn{2}{|c|}{ Hemoglobin (g/dl) } \\
\hline $\begin{array}{l}>13.5 \\
11-13.5 \\
<11\end{array}$ & $\begin{array}{l}0 \\
1 \\
2\end{array}$ \\
\hline \multicolumn{2}{|c|}{ Serum Sodium (mmol/L) } \\
\hline $\begin{array}{l}\geq 135 \\
<135\end{array}$ & $\begin{array}{l}0 \\
2\end{array}$ \\
\hline \multicolumn{2}{|c|}{ Serum Creatinine (mg/dl) } \\
\hline $\begin{array}{l}\leq 1.6 \\
>1.6\end{array}$ & $\begin{array}{l}0 \\
2\end{array}$ \\
\hline \multicolumn{2}{|c|}{ Serum Glucose (mg/dl) } \\
\hline $\begin{array}{l}\leq 180 \\
>180\end{array}$ & $\begin{array}{l}0 \\
1\end{array}$ \\
\hline \multicolumn{2}{|c|}{ Types of NF based on microorganisms } \\
\hline Type I & $\begin{array}{l}\text { NF comprised of synergistic polymicrobial } \\
\text { infection }\end{array}$ \\
\hline Type II & $\begin{array}{l}\text { NF is caused by monomicrobial gram positive } \\
\text { organisms }\end{array}$ \\
\hline Type III & $\begin{array}{l}\text { NF involves gram negative monobacteria usually } \\
\text { marine-related organisms }\end{array}$ \\
\hline Type IV & NF is caused by fungal infection \\
\hline
\end{tabular}

The standard dressing management: After the initial debridement, the surgeon would use antiseptic soaked gauze dressing to absorb the expected post-debridement ooze. Following an adequate debridement, wet to dry dressings started 2-3 times a day to achieve gentle debridement of residual sloughs and debris otherwise difficult to clear surgically. Once clean wound is achieved, a vacuum assisted closure (VAC) could be used to enhance healing and formation of healthy granulation tissues and reduce wound surface area. The plan for secondary closure is often discussed with reconstructive plastic surgeons at early stage.

\section{Statistical analysis}

Data were presented as proportions, median (range) or mean ( \pm standard deviation), as appropriate. Baseline demographic characteristics, medical history, SOFA score on admission, initial procalcitonin (PCT) levels and outcomes were compared between the two groups according to LRINEC values on admission. Analyses were conducted using Student $t$ test or ANOVA test for 
continuous variables and Pearson chi-square $\left(\chi^{2}\right)$ test for categorical variables, whenever applicable. Nonparametric Mann-Whitney test was used for skewed variables. A 2-tailed $p<0.05$ was considered significant. Receiver-operator characteristic curves were plotted to identify LRINEC cut-off point for predicting septic shock and mortality. Area under the curve (AUC) was used to compare the discriminatory power of the scoring system or other clinical variables of interest, with an AUC 1.0 considered perfect discrimination and 0.5 considered equal to chance [19]. The correlation between LRINEC and SOFA values was performed using Pearson correlation that was considered significant at the 0.01 level (2-tailed). We also sub-analyzed data to look for outcomes in a subset of patients with no records of LRINEC scores to avoid selection bias. Data analysis was carried out using the Statistical Package for Social Sciences version 18 (SPSS Inc, Chicago, Illinois).

\section{Results}

During the study period, 331 NF cases were hospitalized and LRINEC score was successfully calculated in 294 cases. One hundred and thirty three (45\%) of these patients were included in Group 1 and 161 (55\%) in Group 2. Mean LRINEC score on admission was $6.28 \pm$ 2.9. Figure 1 shows the normal distribution of mean LRINEC scores. Males were predominant in the overall patient cohort $(217 ; 73.8 \%)$; and the proportion of patients by gender was comparable between the 2 groups $(p=0.82)$. Table 2 summarizes patients' characteristics in the 2 study groups. The mean age of patients was $50.9 \pm$ 15 years. When compared to Group 1, patients in Group 2 were five years older (mean age $53.1 \pm 15.7 \mathrm{vs}$. $48.4 \pm$ 14.9 years, $p=0.009$ ); more likely to have comorbidities such as DM (61.4 vs $41.5 \%, p<0.001)$; hypertension ( 46.8 vs. $21.5 \%, p=0.001$ ); and renal disease (20.3 vs. $10.0 \%, p=0.02)$. Group 2 also had higher proportion of pseudomonas aeruginosa infections than those in Group 1 (11.7 vs. $2.4 \%, p=0.004)$. LRINEC values were higher in NF type IV, however, no significant statistical differences between the two groups were seen in terms of the other microorganisms, or site of infections (Table 3).

The confirmatory histopathology was found in 192 patients (65\%), whereas there were no histopathology data available for the remaining patients. However, the mean LRINEC scores were almost similar in patients who had histopathology and those who had no histopathology reports (6.1 vs 6.4 points).

Initial PCT levels [median 8 (0.07-303) vs. 0.8 (0.09-182)] and SOFA score on admission $(11.6 \pm 3.3$ vs $8.7 \pm 2.4$, $p=0.001$ ) were greater in Group 2 patients than those in Group 1. Pearson correlation for LRINEC and SOFA scores showed moderate correlation: $r=0.51, p<0.001)$. The intensive care duration (median 7 (1-75) vs 5 (2-34)

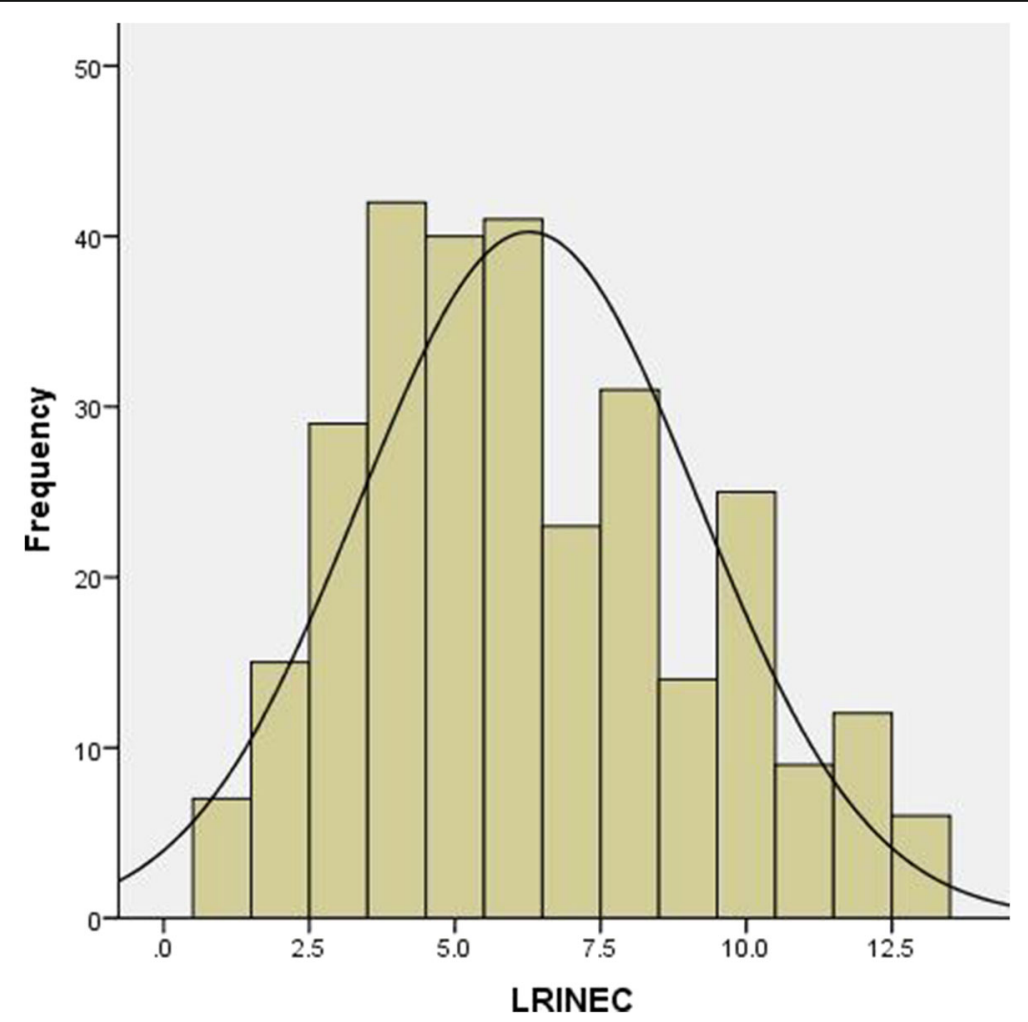

Fig. 1 Frequency of LRINEC scoring $[\mathrm{n}=294$, mean \pm SD $(6.3 \pm 2.9)]$ 
Table 2 Demographics, comorbidities, region of infection and outcomes in patients with NF

\begin{tabular}{|c|c|c|c|}
\hline & LRINEC <6 (45\%) & LRINEC $\geq 6$ (55\%) & $P$ \\
\hline Age, years (mean $\pm S D)$ & $48 \pm 15$ & $53 \pm 16$ & 0.009 \\
\hline Males (\%) & 74 & 73 & 0.82 \\
\hline Diabetes Mellitus (\%) & 41.5 & 61.4 & 0.001 \\
\hline Kidney disease \% & 10 & 20 & 0.02 \\
\hline Hypertension\% & $28(21.5)$ & $74(46.8)$ & 0.001 \\
\hline \multicolumn{4}{|l|}{ Site of infection \% } \\
\hline Lower limbs & 49 & 55 & 0.32 \\
\hline Perineum \& genitalia & 35.3 & 34.8 & 0.92 \\
\hline Abdominal and groin & 12.0 & 8.7 & 0.34 \\
\hline Chest \& breast & 3.0 & 2.5 & 0.78 \\
\hline Face \& neck & 6.0 & 7.5 & 0.62 \\
\hline Number of debridement & $2.14 \pm 1.5$ & $2.09 \pm 1.3$ & 0.81 \\
\hline \multicolumn{4}{|c|}{ Number of antibiotics used ${ }^{\mathrm{a}}(\%)$} \\
\hline$\leq 2$ & 81 (78.6) & $83(56.8)$ & \multirow{2}{*}{$\begin{array}{l}0.001 \text { for } \\
\text { all }\end{array}$} \\
\hline$>2$ & $22(21.4)$ & $63(43.2)$ & \\
\hline Hospital LOS; days & $11(2-115)$ & $22(2-129)$ & 0.001 \\
\hline $\begin{array}{l}\text { intensive care LOS; } \\
\text { days }\end{array}$ & $5(2-34)$ & $7(1-75)$ & 0.01 \\
\hline Septic shock (\%) & 15 & 37 & 0.001 \\
\hline Mortality (\%) & 15 & 28.8 & 0.005 \\
\hline
\end{tabular}

${ }^{a}$ Frequently used antibiotics are Tazocin, Clindamycin, Meropenem and Agumentin

days and hospital length of stay [22 (2-129) vs 11 (2-115) days, $p=0.001]$ were greater in the Group 2 patients. Septic shock and mortality rates were 26 and $22 \%$ respectively in the cohort. The proportion of septic shock (37.1\% vs. $15.2 \%, p=0.001$ ) and mortality (28.8 vs. $15.1, p=0.005$ ) were higher in Group 2 patients than Group 1 (Table 2). Also, significantly a higher proportion of patients in Group- 2 required administration of more than two types of antibiotics $(43.2 \%$ vs. $21.4 \%$; $p=0.001)$. Age-adjusted LRINEC values as predictors of septic shock and mortality are shown in Table 4.

Temporal relationship between mortality and LRINEC scores Time to death in NF patients based on the LRINEC scoring is shown in Fig. 2. Although this Boxplot chart

Table 4 Predictors of hospital outcomes in NF

\begin{tabular}{llll}
\hline & \multicolumn{3}{c}{ Risk of Mortality } \\
\cline { 2 - 4 } & Odds ratio & $95 \% \mathrm{Cl}$ & $P$ value \\
\hline LRINEC score & 1.20 & $1.09-1.29$ & 0.01 \\
Age & 1.07 & $1.04-1.09$ & 0.001 \\
& \multicolumn{2}{c}{ Risk of Septic Shock } & \\
LRINEC score & 1.30 & $1.15-1.41$ & 0.001 \\
Age & 1.02 & $1.001-1.041$ & 0.042 \\
\hline
\end{tabular}

Table $\mathbf{3}$ Laboratory results

\begin{tabular}{|c|c|c|c|}
\hline & $\begin{array}{l}\text { LRINEC }<6 \\
(45 \%)\end{array}$ & $\begin{array}{l}\text { LRINEC } \geq 6 \\
(55 \%)\end{array}$ & $P$-value \\
\hline Streptococcus (\%) & $51(40.8)$ & $45(33.1)$ & 0.19 \\
\hline Staphylococcus (\%) & 47(37.6) & $49(35.8)$ & 0.76 \\
\hline Bacteroides (\%) & $30(24.0)$ & $26(18.9)$ & 0.32 \\
\hline Escherichia coli (\%) & $15(12)$ & $16(11.6)$ & 0.92 \\
\hline Pseudomonas (\%) & $3(2.4)$ & $16(11.7)$ & 0.004 \\
\hline Proteus mirabilis (\%) & $0(0)$ & $5(3.6)$ & 0.06 \\
\hline Gram positive (\%) & $94(82.5)$ & $99(76.2)$ & 0.09 \\
\hline Gram negative (\%) & $48(42.1)$ & $71(54.6)$ & 0.08 \\
\hline \multicolumn{4}{|l|}{ Causative bacteria (\%) } \\
\hline Type I (polybacterial) (\%) & $36(31.6)$ & $38(29.2)$ & 0.06 for all \\
\hline Type II (Monobacterial) (\%) & $70(61.4)$ & $70(53.8)$ & \\
\hline Type III (Murine bacteria) (\%) & $0(0)$ & $0(0)$ & \\
\hline Type IV (Fungal) (\%) & $8(7.0)$ & $22(16.9)$ & \\
\hline $\begin{array}{l}\text { C-Reactive protein level, } \\
\text { mean } \pm S D\end{array}$ & $119 \pm 82$ & $249 \pm 111$ & 0.001 \\
\hline $\begin{array}{l}\text { Initial Procalcitonin level, } \\
\text { median (range) }\end{array}$ & 0.85(0.09-182) & $8.1(0.07-303)$ & 0.127 \\
\hline \multicolumn{4}{|l|}{ SOFA score } \\
\hline Mean & $8.7 \pm 2.4$ & $11.6 \pm 3.3$ & 0.001 \\
\hline Median & $8(2-19)$ & $11(4-21)$ & \\
\hline \multicolumn{4}{|l|}{ LRINEC score } \\
\hline Mean & $3.7 \pm 1.1$ & $8.4 \pm 2.1$ & 0.001 \\
\hline Median & $4(1-5)$ & $8(6-13)$ & \\
\hline
\end{tabular}

shows a U-shape death pattern, the majority of deaths occurred after the first week of admission (83\%). The mean LRINEC scores were higher for those who died after the first week (late) and within the first 2 days post-admission(early) than who died between the $3^{\text {rd }}$ and $7^{\text {th }}$ day post-admission $(7.7 \pm 3.0,7.2 \pm 3.3$ and $2.1 \pm$ 1.0 , respectively), $p=0.03$.

The cut-off point of LRINEC scoring for predicting septic shock was 5 points (sensitivity $82 \%$ and specificity $38 \%$ ) whereas the cut-off point for predicting mortality was 8 points (sensitivity $81 \%$ and specificity $36 \%$ ). Figures 3 and 4 demonstrate the ROC curves for LRINEC scoring points in the prediction of septic shock and mortality.

Table 5 shows a sub-analysis including patients in whom LRINEC scoring was not calculated or documented $(n=37)$. Patients without LRINEC scoring had the lowest SOFA score in comparison to the other LRINEC groups. Patients in Group 2 had higher rates of septic shock and mortality than Group 1 as well as the non-documented LRINEC group.

\section{Discussion}

In patients with NF, early diagnosis, simplified risk stratification and on-time, appropriate surgical debridement are 


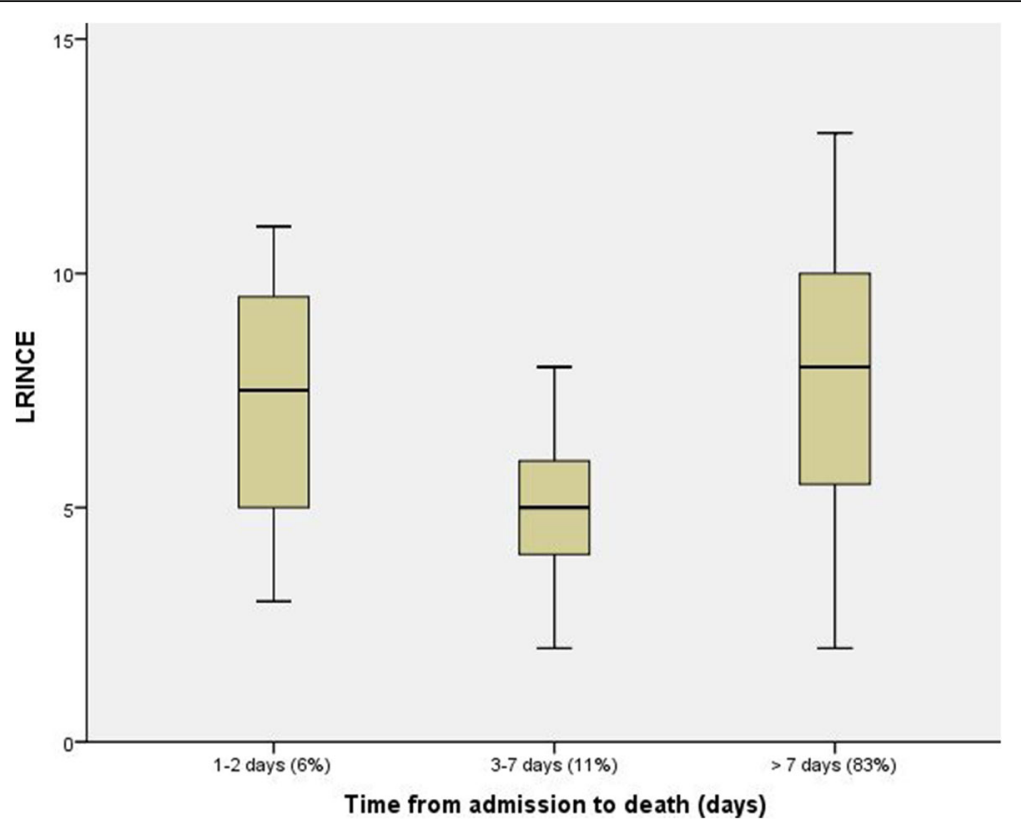

Fig. 2 A Boxplot chart of the time to death in NF patients based on the LRINEC scoring

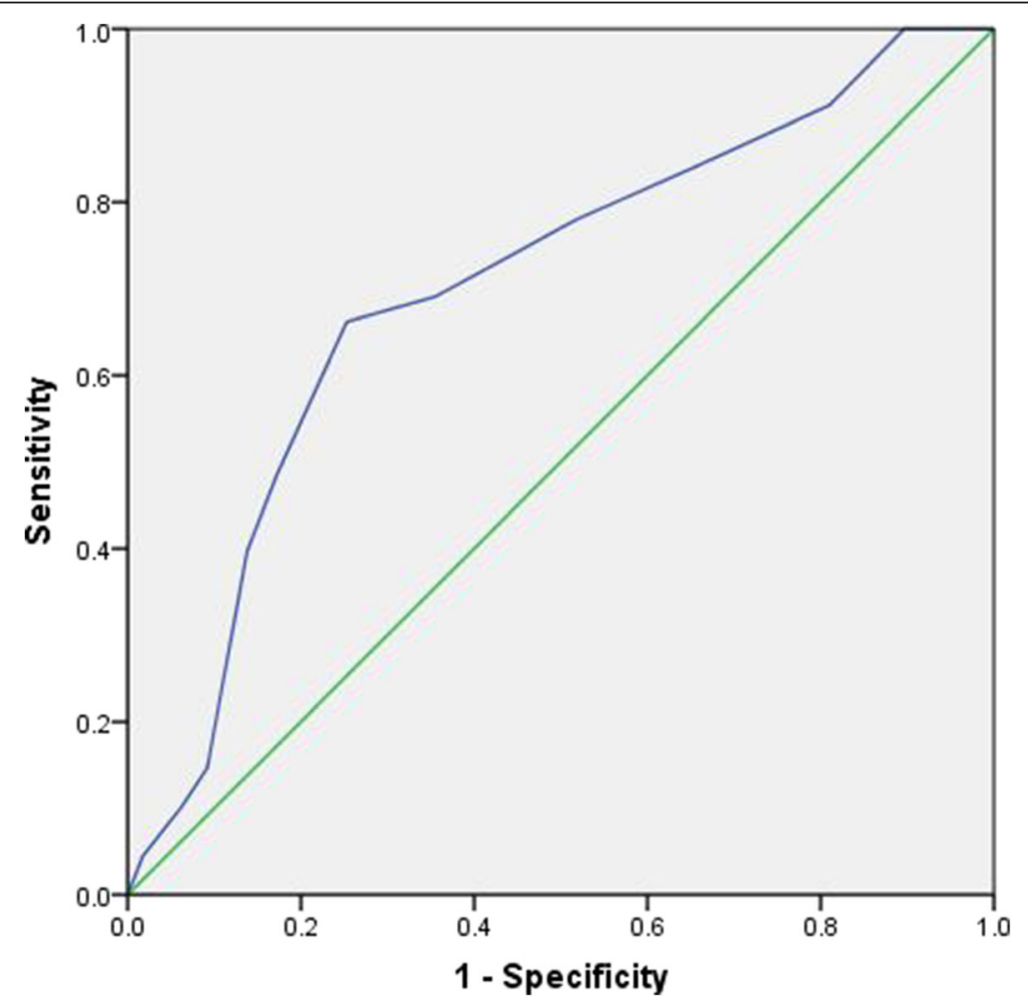

Fig. 3 ROC curve for LRINEC scoring points in the prediction of septic shock: Area under the curve 0.70 ; $95 \%$ confidence interval $0.63-0.78$, $\mathrm{p}<0.001$. LRINEC scoring cut-off value 5 with $82 \%$ sensitivity and $72 \%$ specificity 


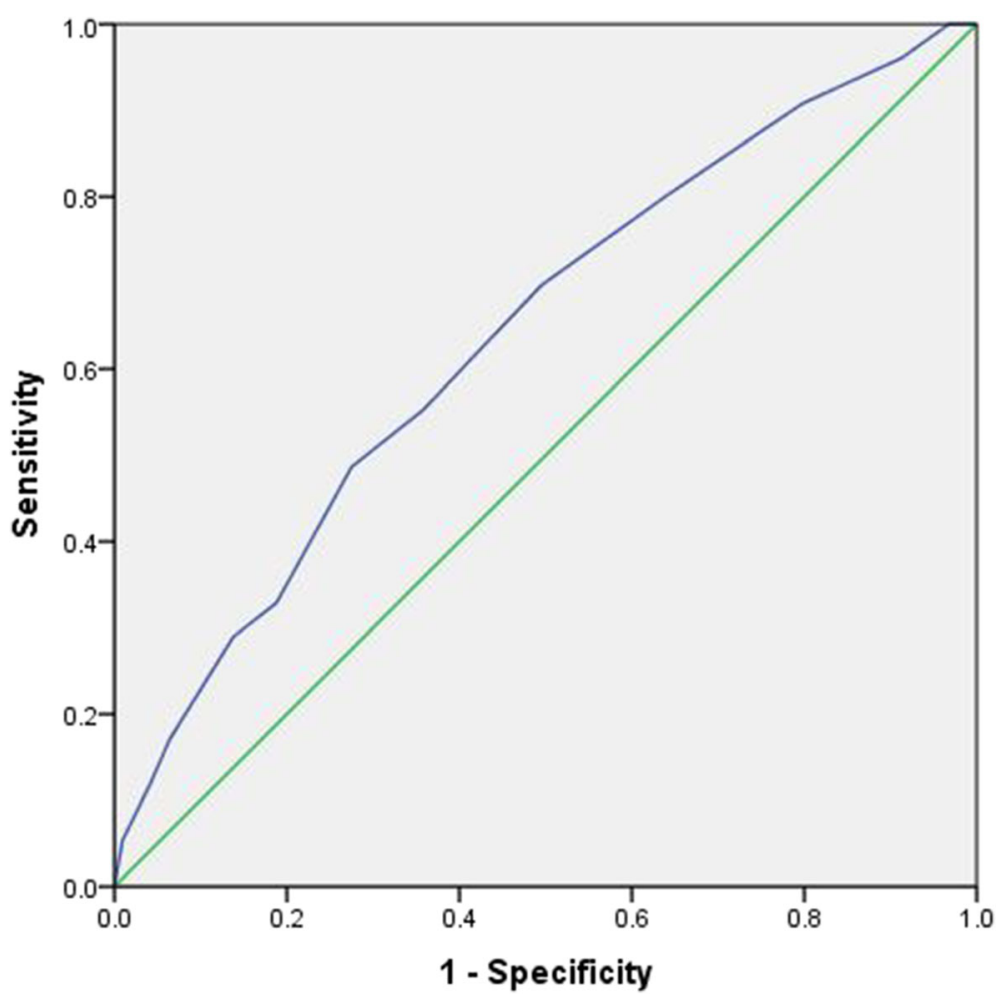

Fig. 4 ROC curve for LRINEC scoring points in the prediction of mortality: Area under the curve $0.64 ; 95 \%$ confidence interval $0.57-0.71$, $p<0.001$. LRINEC scoring cut- off value 8.5 with $81 \%$ sensitivity and $36 \%$ specificity

crucial to achieve better outcomes $[9,20]$. There are few studies which indicate that LRINEC scoring is a useful diagnostic tool with a potential prognostic value. Although most of these studies were not primarily aiming at the evaluation of the prognostic role of LRINEC score, it revealed poor outcomes in NF patients with high LRINEC scores [5, 12, 14-16]. Moreover, most of these studies were characterized by being of small sample size (15-209 cases). The present study aims primarily to assess the prognostic value of LRINEC in 294 NF patients. In our study, male to female ratio was relatively higher (2.8) in comparison to prior studies (1.7 to 2.3), however, the average age of patients (51 years) was comparable. Increased age and other comorbidities such as DM, hypertension, obesity, peripheral vascular disease and renal impairment were found to be associated with

Table 5 Outcomes based on LRINEC status

\begin{tabular}{lllll}
\hline & $\begin{array}{l}\text { Not } \\
\text { available }\end{array}$ & $\begin{array}{l}\text { LRINEC } \\
<6 \text { (group1) }\end{array}$ & $\begin{array}{l}\text { LRINEC } \\
\geq 6 \text { (group2) }\end{array}$ & $P$ \\
\hline $\begin{array}{l}\text { Patients number } \\
\text { SOFA score; }\end{array}$ & 37 & 133 & 161 & \\
$\begin{array}{l}\text { mean } \pm \text { SD } \\
\text { Septic shock \% }\end{array}$ & $25.6 \pm 1.1$ & $8.7 \pm 2.3$ & $11.5 \pm 3.3$ & 0.001 \\
Mortality\% & 18.9 & 15.2 & 37 & 0.001 \\
\hline
\end{tabular}

unfavorable outcomes including limb loss and mortality in NF patients $[1,14,16,21,22]$. Notably, DM is the most common co-morbidity reported in NF patients; with a prevalence of up to 2 out of 3 cases [5, 13-16]. In our series, DM, hypertension and kidney diseases were the most frequent comorbidities in patients with LRINEC score $\geq 6$.

Similar to the previous study of Glass et al study; streptococcus was the most frequently identified pathogen in the present cohort [23]. However, there was no difference between the two LRINEC study groups in terms of the other causative organisms except for pseudomonas species. Patients with higher LRINEC scores were more likely affected by pseudomonas. Colak et al demonstrated that pseudomonas aeruginosa infection was significantly higher in the non-surviving group when compared to the survivors [15].

The biological variables used to calculate LRINEC scoring are found to correlate individually with the diagnosis of NF in some studies. For example, a prospective observational study showed that WBC count $>15,400$ / microL or serum sodium $<135 \mathrm{mEq} / \mathrm{L}$ significantly increased likelihood of NF diagnosis [20]. Wong et al found the cut-off value for the LRINEC score to detect early cases of NF as 6 points with a positive predictive value of $92 \%$ and negative predictive value of $96 \%$ [9]. 
Chao et al [10] demonstrated that in 125 patients diagnosed with NF, LRINEC score of $\geq 2$ had a sensitivity of $71 \%$, a specificity of $83 \%$, with an 12 -fold increased risk for the presence of NF due to Vibiro vulnificus $(n=72)$. Holland et al also in a small retrospective study $(n=28)$, evaluated the effectiveness of LRINEC cut-off score $\geq$ six [24]. This cut-off score showed a sensitivity of $80 \%$, specificity of $67 \%$, a positive predictive value of $57 \%$ and a negative predictive value of $86 \%$ in distinguishing patients with proven NF from those with severe soft tissue infections [24]. However, the negative predictive value of LRINEC was questioned recently in a cohort of 24 patients with histologically confirmed NF [23].

There are few case-reports assessed the applicability of LRINEC score in the diagnosis of NF. Wilson and Schneir reported a case of NF confirmed at surgery where LRINEC score was zero [25]. Whereas, Kulkarni et al reported a sharp increase in LRINEC score (from $7-11)$ in one case on the $5^{\text {th }}$ day of admission due to an increase in CRP level [2]. Despite of the early diagnosis and aggressive intervention, that patient was not survived due to immunocompromised condition and aggressive polybacterial infection.

The prognostic potential of LRINEC score has been reported in few studies as shown in Table $6[5,12,14-16]$.

Table 6 Summary of studies on the prognostic role of LRINEC in NF patients

\begin{tabular}{|c|c|c|c|}
\hline Study & Country & Design & Results \\
\hline Su et al. [5] & Taiwan & $\begin{array}{l}\text { Retrospective study } \\
(2002-2005) \\
N=209\end{array}$ & $\begin{array}{l}\text { Patients with a LRINEC } \\
\text { score of } \geq 6 \text { have a higher } \\
\text { rate of both mortality and } \\
\text { amputation. }\end{array}$ \\
\hline $\begin{array}{l}\text { Corbin } \\
\text { et al. [12] }\end{array}$ & France & $\begin{array}{l}\text { Prospective study } \\
N=50\end{array}$ & $\begin{array}{l}\text { The rate of complications } \\
\text { was higher for patients with } \\
\text { a LRINEC score }>6 \text { than for } \\
\text { patients with a score }<6 \text {. }\end{array}$ \\
\hline $\begin{array}{l}\text { Swain } \\
\text { et al. [14] }\end{array}$ & UK & $\begin{array}{l}\text { Retrospective study } \\
(2006-2011) \\
N=15\end{array}$ & $\begin{array}{l}\text { Overall mortality was } 3 \text { out } \\
\text { of } 15 \text { patients. The median } \\
\text { LRINEC score in all deaths } \\
\text { was } 9.0 \text { (range: } 6-12 \text { ). }\end{array}$ \\
\hline $\begin{array}{l}\text { Bozkurt } \\
\text { et al. [16] }\end{array}$ & Turkey & $\begin{array}{l}\text { Retrospective study } \\
(2008-2013) \\
N=33\end{array}$ & $\begin{array}{l}\text { Patients with higher LRINEC } \\
\text { scores were more likely to } \\
\text { require mechanical ventilation } \\
\text { and longer hospitalization } \\
\text { times and were more likely } \\
\text { to die }\end{array}$ \\
\hline $\begin{array}{l}\text { COLAK } \\
\text { et al. [15] }\end{array}$ & Turkey & $\begin{array}{l}\text { Retrospective study } \\
(2008-2013 \\
N=25\end{array}$ & $\begin{array}{l}\text { The mean number of } \\
\text { debridements and LRINEC } \\
\text { score were higher in the } \\
\text { non-surviving group ( } p=0.003 \\
\text { and } p=0.003 \text {, respectively). }\end{array}$ \\
\hline $\begin{array}{l}\text { El-Menyar } \\
\text { et al. } 2017\end{array}$ & Qatar & $\begin{array}{l}\text { Retrospective study } \\
2000-2013 \\
N=294\end{array}$ & $\begin{array}{l}\text { LRINEC } \geq 6 \text { had greater SOFA } \\
\text { score }(11.5 \pm 3 \text { vs } 8 \pm 2) \\
\text { septic shock ( } 37 \% \text { vs } 15 \%) \text {, } \\
\text { prolonged hospital length } \\
\text { of stay and deaths } \\
(p<0.001 \text { for all) }\end{array}$ \\
\hline
\end{tabular}

$\mathrm{Su}$ et al studied the LRINEC cut-off value associated with poor outcomes in $209 \mathrm{NF}$ patients and demonstrated higher mortality and amputation rates in patients based on LRINEC scores [5]. The rates of early diagnosis (64 vs $70 \%$ ), early operation (71 vs $70 \%$ ) and time for operation ( $30 \pm 51$ vs $27.5 \pm 51 \mathrm{~min}$ ) were comparable between the 2 LRINEC groups. The overall mortality and amputation rates were 16 and $26 \%$, respectively. Whereas, the rates of mortality ( $21 \%$ vs. $11 \%)$ and amputation (36\% vs. $17 \%)$ in patients with LRINEC score $\geq 6$ were higher than those who had LRINEC $<6$ [5].

Corbin et al prospectively studied the prognostic value of LRINEC score in 50 patients [12]. The rate of complications (septic shock, transfer to intensive care and mortality) in NF patients with LRINEC $\geq 6$ was higher when compared to the patients with score $<6$. Bozkurt et al evaluated this capability of LRINEC in predicting the morbidity and mortality in patients with Fournier's gangrene $(n=33)$ [16]. In that study, LRINEC score effectively predicted the requirement of mechanical ventilation and mortality. Colak et al also found that high LRINEC scoring might predict the requirement of debridement and mortality in NF patients $(n=25)$ [15]. Our study is in consistency with these reports that showed significantly higher mortality and septic shock rates in patients with LRINEC score $\geq 6$. In addition, the duration of stay in ICU and hospital were significantly longer among patients with higher scores. Also, the present study showed that although the number of debridement was comparable in the 2 LRINEC groups, the number of antibiotics used was higher in patients with greater LRINEC scoring. Our analysis showed that the number of NF- related in-hospital deaths was increasing over the time. Notably, the mortality and LRINEC scores had a U-shape relationship. The mean scores were significantly greater in those who died after the first week of admission in contrast to its lower value in those who died between the $3^{\text {rd }}$ and $7^{\text {th }}$ day.

Of note, the other severity scoring systems like APACHE and SOFA were scarcely tested as predictors of outcome in patients with NF, and if so, this was as a surrogate outcome [26-30]. Patients with SOFA scores of more than $>8$ were found to deserve urgent admission to the surgical intensive care and also to be associated with poor outcome in patients with NF $[26,30]$.

In our study, SOFA was significantly higher in patients with LRINEC $\geq 6$ (mean SOFA 11.6 \pm 3.3 ) when compared to patients with LRINEC $<6$ (mean SOFA $8.7 \pm$ 2.4). Our analysis demonstrated that Pearson correlation for LRINEC and SOFA scores showed a moderate correlation $(p<0.001)$. LRINEC cut-off value for predicting hospital mortality was 8 points in our study. Notably, Swain et al reported $20 \%$ mortality in their NF patient population, and the median LRINEC score of all patients 


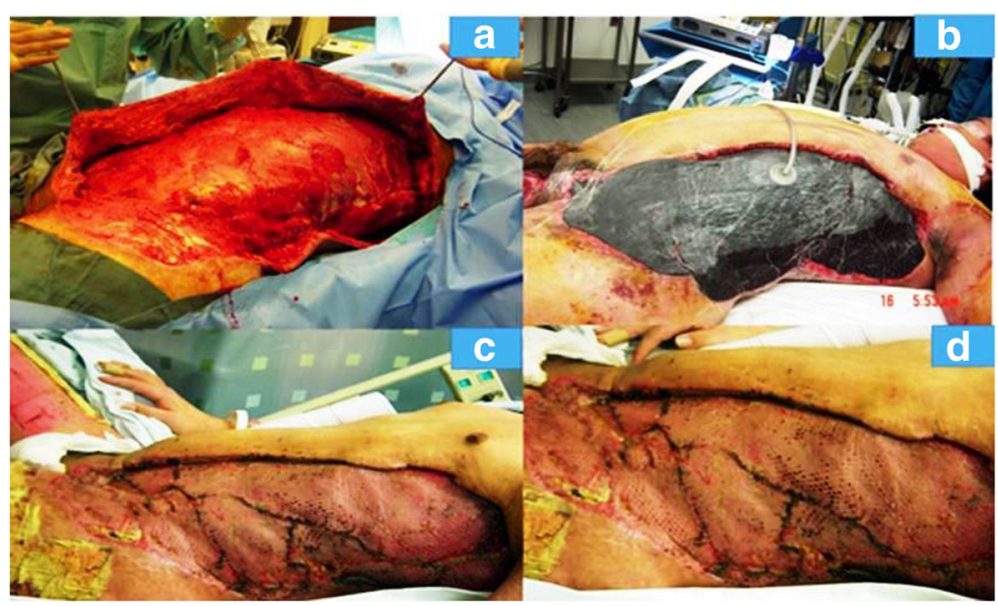

Fig. 5 Patient with NF of left chest wall extending from left axilla to left groin and scrotum. a) Post-surgical debridement of the chest and abdominal wall; b) Wound VAC placement on the same patient; $\mathbf{c} \& \mathbf{d}$ : Two consecutive images of reconstruction of the same wound with skin graft

who died was nine [14]. However, the low specificity for LRINEC cut-off for predicting mortality (cut off value $=8$, sensitivity $81 \%$ and specificity $36 \%$ ) as well as septic shock (cut off value $=5$, sensitivity $82 \%$ and specificity $38 \%$ ) are of concern and need further prospective evaluation. Furthermore, research work is still needed to determine the utility of LRINEC scoring and to validate its prognostic role in the hospital outcomes in patients with NF.

Finally, one of the most important elements of NF is the surgical management, which needs to commence as soon as possible [31] in terms of consist of aggressive and wide debridement. More often than note, these patients undergo a number of debridements and meticulous wound management including the nowadays VAC and skin graft reconstruction (Fig. 5).

\section{Limitations}

The retrospective nature of this study is a limitation to fill the gaps and to generalize the results. There were 37 cases (out of the $331 \mathrm{NF}$ patients) in which LRINEC scoring was not available in our database, however, we analyzed their data to avoid selection bias. The mortality rate was $18.9 \%$ in this subgroup (no LRINEC) in comparison to $28.6 \%$ in high LRINEC group and $15 \%$ in the low LRINEC scoring group. This finding supports the need to measure LRINEC in all NF cases. The reason behind missing LRINEC in some cases was not clearly identified. According to database registry, confirmatory hisopathology results were not available for one third of the cases. Further, prospective studies are needed to validate the scoring system for this purpose. Determination of the time interval between the diagnosis and treatment (medical and surgical) could possibly influence the outcome in the NF patients as there is evidence that delayed first debridement is often associated with poor outcomes
[20], while operating early has reduced hospital and ICU length of stay [31]. Also, the effect of possible prior antibiotic treatment from other facilities was not addressed or reported. The percent total body surface as well as the exact time intervals for debridement and dressings was not studied. Therefore, we are currently using this observation as an audit to fix these gaps.

\section{Conclusions}

In patients presented with NF, LRINEC scoring, in addition to its diagnostic role, could be used for risk stratification and prognosis. Further prospective studies are needed to support and validate our findings.

\section{Abbreviations}

APACHE: Acute Physiology and Chronic Health Evaluation; LRINEC: The Laboratory Risk Indicator for Necrotizing Fasciitis; NF: Necrotizing fasciitis; SOFA: Sequential Organ Failure Assessment; WBC: white blood cell count

\section{Acknowledgements}

We thank the surgical intensive care unit staff, and all the database registry staff of the trauma section Hamad General Hospital.

This study was presented in part at the $16^{\text {th }}$ European Congress of Trauma and Emergency Surgery, May 10-12, 2015, Amsterdam, The Netherlands.

\section{Funding}

This research did not receive any specific grant from any funding agency in the public, commercial or not-for-profit sector.

\section{Availability of data and materials}

Data are available if needed after getting permission and agreement from the medical research center (research@hamad.qa)

\section{Authors' contributions}

All authors have read and approved the manuscript, AE: conception and design of the study, interpretation of data, writing manuscript and critical review of manuscript; MA: acquisition of data, writing manuscript and review of manuscript; IM: acquisition of data, writing manuscript and critical review of manuscript; AMK: acquisition of data, writing manuscript and critical review of manuscript; RL: writing manuscript and critical review of manuscript HA: study design, draft manuscript and critical review of manuscript. 


\section{Competing interests}

The authors declare that they have no competing interests.

\section{Consent for publication}

Not applicable.

\section{Ethics approval and consent to participate}

A waiver of consent was granted and this study was approved by the medical research center at HMC, Qatar with IRB\#14066/14.

\section{Author details}

${ }^{1}$ Clinical Medicine, Weill Cornell Medical School, Doha, Qatar. ${ }^{2}$ Clinical Research, Trauma Surgery, Hamad General Hospital (HGH), Doha, Qatar. ${ }^{3}$ Department of Surgery, Intensive Care Unit, HGH, Doha, Qatar. ${ }^{4}$ Department of Surgery, Westchester Health, Valhalla, NY, USA. ${ }^{5}$ Department of Surgery, trauma Surgery, HGH, Doha, Qatar. ${ }^{6}$ Weill Cornell medical college, Clinical Research, Trauma Surgery, Hamad General Hospital, Doha, Qatar.

Received: 1 October 2016 Accepted: 6 February 2017

Published online: 07 March 2017

\section{References}

1. Krieg A, Dizdar L, Verde PE, et al. Predictors of mortality for necrotizing softtissue infections: a retrospective analysis of 64 cases. Langenbecks Arch Surg. 2014:399(3):333-41.

2. Kulkarni M, Vijay Kumar G, Sowmya G, et al. Necrotizing Soft-Tissue Infection: Laboratory Risk Indicator for Necrotizing Soft Tissue Infections Score. J Lab Physicians. 2014;6(1):46-9.

3. Magala J, Makobore P, Makumbi T, et al. The clinical presentation and early outcomes of necrotizing fasciitis in a Ugandan Tertiary Hospital-a prospective study. BMC Res Notes. 2014;7:476. doi:10.1186/1756-0500-7-476.

4. Misiakos EP, Bagias G, Patapis P, Machairas A, et al. Current concepts in the management of necrotizing fasciitis. Front Surg. 2014;1:36. doi:10.3389/fsurg. 2014.00036

5. Su YC, Chen HW, Hong YC, et al. Laboratory risk indicator for necrotizing fasciitis score and the outcomes. ANZ J Surg. 2008:78:968-72.

6. Wall DB, Klein SR, Black S, et al. A simple model to help distinguish necrotizing fasciitis from nonnecrotizing soft tissue infection. J Am Coll Surg. 2000;191:227-31.

7. Huang KF, Hung MH, Lin YS, et al. Independent predictors of mortality for necrotizing fasciitis: a retrospective analysis in a single institution. J Trauma. 2011;71:467-73. discussion 473

8. Shiroff AM, Herlitz GN, Gracias VH. Necrotizing soft tissue infections. J Intensive Care Med. 2014;29:138-44.

9. Wong $\mathrm{CH}$, Khin LW, Heng KS, et al. The LRINEC (Laboratory Risk Indicator for Necrotizing Fasciitis) score: a tool for distinguishing necrotizing fasciitis from other soft tissue infections. Crit Care Med. 2004;32:1535-41.

10. Chao WN, Tsai SJ, Tsai CF, et al. The Laboratory Risk Indicator for Necrotizing Fasciitis score for discernment of necrotizing fasciitis originated from Vibrio vulnificus infections. J Trauma Acute Care Surg. 2012;73:1576-82.

11. Thomas AJ, Meyer TK. Retrospective evaluation of laboratory-based diagnostic tools for cervical necrotizing fasciitis. Laryngoscope. 2012;122:2683-7.

12. Corbin V, Vidal M, Beytout J, et al. Prognostic value of the LRINEC score (Laboratory Risk Indicator for Necrotizing Fasciitis) in soft tissue infections: a prospective study at Clermont-Ferrand University hospital. Ann Dermatol Venereol. 2010;137:5-11.

13. Citak M, Backhaus M, Tilkorn DJ, et al. Necrotizing fasciitis in patients with spinal cord injury: an analysis of 25 patients. Spine. 2011;36:E1225-9.

14. Swain RA, Hatcher JC, Azadian BS, et al. A five-year review of necrotising fasciitis in a tertiary referral unit. Ann R Coll Surg Engl. 2013;95:57-60.

15. Colak E, Ozlem N, Kucuk GO, et al. Laboratory Risk Indicators for Necrotizing Fasciitis and Associations with Mortality. Turk J Emerg Med. 2014;14:15-9.

16. Bozkurt $\mathrm{O}$, Sen $\mathrm{V}$, Demir $\mathrm{O}$, et al. Evaluation of the utility of different scoring systems (FGSI, LRINEC and NLR) in the management of Fournier's gangrene. Int Urol Nephrol. 2015;47:243-8

17. Vincent JL, Moreno R, Takala J, et al. The SOFA (Sepsis-related Organ Failure Assessment) score to describe organ dysfunction/failure. On behalf of the Working Group on Sepsis-Related Problems of the European Society of Intensive Care Medicine. Intensive Care Med. 1996;22:707-10.
18. Shaikh N, Khawaiter J, Al-Thani H. Necrotizing Fasciitis: A Surgical and Medical Emergency. Surg Sci. 2012;3:518-25. http://dx.doi.org/10.4236/ss. 2012.311103.

19. Hanley JA, McNeil BJ. The meaning and use of the area under a receiver operating characteristic (ROC) curve. Radiology. 1982;143:29-36.

20. Chan T, Yaghoubian A, Rosing D, et al. Low sensitivity of physical examination findings in necrotizing soft tissue infection is improved with laboratory values: a prospective study. Am J Surg. 2008;196:926-30.

21. Zacharias N, Velmahos GC, Salama A, et al. Diagnosis of necrotizing soft tissue infections by computed tomography. Arch Surg. 2010;145:452-5.

22. Kao LS, Lew DF, Arab SN, et al. Local variations in the epidemiology, microbiology, and outcome of necrotizing soft-tissue infections: a multicenter study. Am J Surg. 2011;202:139-45.

23. Glass GE, Sheil F, Ruston JC, et al. Necrotizing soft tissue infection in a UK metropolitan population. Ann R Coll Surg Engl. 2015:97:46-51.

24. Holland MJ. Application of the Laboratory Risk Indicator in Necrotising Fasciitis (LRINEC) score to patients in a tropical tertiary referral centre. Anaesth Intensive Care. 2009;37:588-92.

25. Wilson MP, Schneir AB. A case of necrotizing fasciitis with a LRINEC score of zero: clinical suspicion should trump scoring systems. J Emerg Med. 2013;44:928-31.

26. Yeh DD, Velmahos G. Necrotizing Soft Tissue Infections. In: Yelon JA, Luchette FA, editors. Geriatric Trauma and Critical Care. New York: Springer; 2014. p. 161-73.

27. Khamnuan P, Chongruksut W, Jearwattanakanok K, et al. Necrotizing fasciitis: risk factors of mortality. Risk Manag Healthc Policy. 2015;8:1-7.

28. Bolaños-Morales F, Peña E, Guzmán-DeAlba E, et al. Prognostic value of semiquantitative serum Procalcitonine vs APACHE or SOFA scores in patients with descending necrotizing mediastinitis. Eur Respir J. 2015;46: PA1517. doi:10.1183/13993003.congress-2015.PA1517.

29. Bulger EM, May A, Bernard A, et al. Impact and Progression of Organ Dysfunction in Patients with Necrotizing Soft Tissue Infections: A Multicenter Study. Surg Infect (Larchmt). 2015;16:694-701.

30. Shaikh N, Ummunissa F, Hanssen Y, et al. Hospital epidemiology of emergent cervical necrotizing fasciitis. J Emerg Trauma Shock. 2010;3:123-5. doi:10.4103/0974-2700.62108

31. Hadeed GJ, Smith J, O'Keeffe T, et al. Early surgical intervention and its impact on patients presenting with necrotizing soft tissue infections: A single academic center experience. J Emerg Trauma Shock. 2016;9(1):22-7.

\section{Submit your next manuscript to BioMed Central and we will help you at every step:}

- We accept pre-submission inquiries

- Our selector tool helps you to find the most relevant journal

- We provide round the clock customer support

- Convenient online submission

- Thorough peer review

- Inclusion in PubMed and all major indexing services

- Maximum visibility for your research

Submit your manuscript at www.biomedcentral.com/submit
Biomed Central 